\title{
Expression of B7-H3 in hypopharyngeal squamous cell carcinoma as a predictive indicator for tumor metastasis and prognosis
}

\author{
AKIHIRO KATAYAMA, MIKI TAKAHARA, KAN KISHIBE, TOSHIHIRO NAGATO, \\ ISAMU KUNIBE, AKIHIRO KATADA, TATSUYA HAYASHI and YASUAKI HARABUCHI \\ Department of Otolaryngology-Head and Neck Surgery, Asahikawa Medical \\ University, Midorigaoka E 2-1-1-1, Asahikawa, 078-8510, Japan
}

Received November 29, 2010; Accepted January 25, 2011

DOI: 10.3892/ijo.2011.949

\begin{abstract}
B7-H3 is a member of the B7 family thought to be a co-regulatory factor of antigen-specific T-cell immune response via co-stimulatory and co-inhibitory receptors. We evaluated its potential expression in head and squamous cell carcinoma (SCC) cell lines, and in clinical tissue samples obtained from 37 patients with human hypopharyngeal SCC. All head and neck SCC cell lines tested expressed both the B7-H3 gene and cell surface protein. The staining intensity of immunoreactivity by tumor cells was blindly evaluated by two head and neck surgeons and the results were categorized into 4 grades according to staining intensity. Eighty-seven percent of patients expressed B7-H3. B7-H3 expression was inversely correlated with the number of tumor infiltrating $\mathrm{CD}^{+}$ T-cells ( $\mathrm{r}=-0.4339, \mathrm{p}=0.023)$. Patients who developed distant metastasis after tumor-free periods showed significantly higher B7-H3 expression scores compared to patients who did not develop distant metastasis during follow-up periods $(\mathrm{p}=0.048)$. Distant metastasis control ratio in patients with strong B7-H3 expression was significantly lower compared to that in patients with no to intermediate B7-H3 expression ( $\mathrm{p}=0.040)$. Causespecific survival ratio in patients with strong $\mathrm{B} 7-\mathrm{H} 3$ expression was significantly lower compared to that in patients with no to intermediate $\mathrm{B} 7-\mathrm{H} 3$ expression $(\mathrm{p}=0.028)$. Moreover, multivariate analysis revealed that strong B7-H3 expression was an independent prognostic factor in tumor-specific death in hypopharyngeal SCC (hazard ratio: 9.803, confidence interval: $0.018-0.539, \mathrm{p}=0.0110$ ).
\end{abstract}

\section{Introduction}

Hypopharyngeal SCC is one of the most aggressive head and neck tumor. Hypopharyngeal SCC tend to present

Correspondence to: Dr Akihiro Katayama, Department of Otolaryngology-Head and Neck Surgery, Asahikawa Medical University, Midorigaoka E 2-1-1-1, Asahikawa 078-8510, Japan

E-mail:akata@asahikawa-med.ac.jp

Key words: B7-H3, co-regulatory factor, hypopharynx, squamous cell carcinoma, prognostic factor with advanced primary disease, and nodal metastasis is highly likely. The most important features determining prognosis are the size and extent of local spread of the primary carcinoma and the extent of involvement of regional lymph nodes. Distant metastasis at presentation is more common in hypopharyngeal cancers than in other head and neck cancers (1). Approximately $80 \%$ of hypopharyngeal cancer is stage III or IV at presentation, with locally advanced disease present in the majority, and it has been estimated that $20 \%$ are inoperable at the time of diagnosis (2-4). Owing to its extremely high malignant potential, it is usually diagnosed at an advanced stage and often recurs even after curative therapies. Despite recent improvements in diagnostic imaging, radiation and chemotherapy, and improved surgical techniques, there has not been significant impact on the survival of patients with hypopharyngeal SCC (1). Therefore, strenuous efforts to find novel cancer-related molecules for diagnosis and targeted therapeutic procedure will be required to predict and improve prognosis of the patients with hypopharyngeal SCC.

One mechanism that has been reported for tumor-associated immune suppression in certain cancers is the aberrant expression of inhibitory T-cell co-regulatory molecules by tumor cells (5-15). Tumor infiltrating lymphocytes (TIL) are generally thought to represent a host immune response to antigen expressed on tumor cells $(16,17)$. Especially, CD8 ${ }^{+}$ cytotoxic T-cells (CTL) are considered to be the major effectorimmune cells directly against tumor cells. This notion is supported by the observation that cytotoxic TIL are indicators of favorable prognosis in certain cancers (18-20), moreover high density of lymphocytic infiltration has been identified as favorable specific marker in head and neck SCC (21). T-cell co-simulation and co-inhibition are primary generated by interaction between members of B7 family of immune regulatory ligands and their receptors. B7-H3, also known as CD276, is a relative new member of $\mathrm{B} 7$ family, initially identified as a co-stimulator of T-lymphocyte (22). In subsequent studies the immunological stimulatory functions of B7-H3 have been described (23-26). On the other hand, B7-H3 is also thought to serve as an accessory co-inhibitor of T-cell responses, and many studies have been reported suggesting that B7-H3 plays inhibitory roles in T-cell activation (27-29). Although the function of B7-H3 remains controversial, many recent studies on wide variety of cancer tissues demonstrated that 
the aberrant expression is positively associated with cancer progression and poor patients prognosis (13,30-35). To our knowledge, B7-H3 expression in hypopharyngeal SCC has not been examined and reported. Therefore, we explored the expression of B7-H3 in cancer tissues obtained from patients with hypopharyngeal SCC and explored their association with intratumoral CTL infiltration, cancer progression and prognosis.

\section{Patients and methods}

Cell culture. Four human HNSCC cell lines were utilized in this study. Raji cells derived from Burkitt's lymphoma and SK-OV3 cells derived from breast cancer were utilized as negative and positive control cells for B7-H3 expression, respectively. HPC-92Y cells were provided by Dr S. Yanoma (Yokohama Tsurugamine Hospital, Yokohama, Japan). SAS cell were obtained from the American Type Culture Collection (Manassas, VA). PCI-13, PCI-30, SK-OV3 and Raji cells were provided by Dr S. Ferrone (Department of Surgery, University of Pittsburgh Cancer Institute, Pittsburgh, USA). The cell lines were established from following sites: HPC-92Y was from hypopharyngeal SCC, SAS was from tongue SCC, PCI-13 and PCI-30 from oropharyngeal SCC. The cells were cultured in RPMI-1640 (Gibco, Auckland, NZ) medium supplemented with $10 \%$ fetal bovine serum at $37^{\circ} \mathrm{C}$ with $5 \% \mathrm{CO}_{2}$.

Tissue samples. Hypopharyngeal SCC tissue samples were obtained at pre-treatment periods from 37 Japanese patients (35 males and 2 females) with a median age of 63 years (range, 44-81 years) who were treated in Department of Otolaryngology, Asahikawa Medical University between 1999 and 2004. All patients signed informed consent for therapy and tissue studies that had received prior approval by the Institutional Review Board. Clinical and pathological features of the patients are listed in Table I. According to the 2002 UICC TNM staging systems there were: stage I, 3 patients $(8 \%)$, stage II, 5 patients (14\%), stage III, 3 patients $(8 \%)$ and stage IV, 26 patients $(70 \%)$. Twenty eight patients $(76 \%)$ had lymph node metastasis ( $\mathrm{N} 1$ in 3 patients, N2a in 1 patient, N2b in 13 patients, $\mathrm{N} 2 \mathrm{c}$ in 6 patient, $\mathrm{N} 3$ in 5 patients) at diagnosis. None of the patients had distant metastasis at diagnosis. The classification of tumor differentiation was well-differentiated SCC type in 7 patients (19\%), moderately SCC in $26(70 \%)$ and poorly SCC in 4 (11\%). Follow-up periods ranged from 6 to 133 months with a median of 26 months.

$R T-P C R$. Total cellular RNA from HNSCC cell lines was extracted with SV Total RNA Isolation system (Promega Corp., Madison, WI). The first strand cDNA was synthesized using MMLV reverse transcriptase with oligo dT-primers (Invitrogen, Carlsbad, CA, USA) according to manu-facturers instructions. Oligomer primers were synthesized for B7-H3 (sense: 5'-ctctccaaaggaaagcgaggtggacat-3'; antisense: $5^{\prime}$-agactgtacactgtaggtgctgaaatca-3'), $\beta$-actin (sense: $5^{\prime}$-atgggtca gaaggattcctatgt-3'; antisense: 5'-tcaggaggagcaatgatcttga-3') (Integrated DNA Technologies, Coralville, Iowa, USA). PCR was performed in a $10 \mu \mathrm{l}$ reaction mixture containing $4.95 \mu \mathrm{l}$ $\mathrm{H}_{2} \mathrm{O} ; 1 \mu \mathrm{l}$ PCR buffer (contains $15 \mathrm{mM} \mathrm{MgCl} \mathrm{Mg}_{2}, 10$-fold
Table I. Clinical and histologic features in 37 patients with hypopharyngeal squamous cell carcinama.

\begin{tabular}{|c|c|}
\hline Characteristics & No. of cases $(\%)$ \\
\hline \multicolumn{2}{|l|}{ Gender } \\
\hline Female & $35(77 \%)$ \\
\hline Male & $2(23 \%)$ \\
\hline \multicolumn{2}{|c|}{$\begin{array}{l}\text { Age (years): median 63: } \\
\text { range } 44-81\end{array}$} \\
\hline$<65$ & $21(57 \%)$ \\
\hline$\geq 65$ & $16(43 \%)$ \\
\hline \multicolumn{2}{|l|}{ Primary sites } \\
\hline PS & $29(78 \%)$ \\
\hline $\mathrm{PC}$ & $4(11 \%)$ \\
\hline PW & $4(11 \%)$ \\
\hline \multicolumn{2}{|l|}{ Clinical stage } \\
\hline I & $3(8 \%)$ \\
\hline II & $5(14 \%)$ \\
\hline III & $3(8 \%)$ \\
\hline IV & $26(70 \%)$ \\
\hline \multicolumn{2}{|l|}{$\mathrm{N}$ factor } \\
\hline NO & $9(24 \%)$ \\
\hline N1 & $3(8 \%)$ \\
\hline $\mathrm{N} 2 \mathrm{a}$ & $1(3 \%)$ \\
\hline $\mathrm{N} 2 \mathrm{~b}$ & $13(35 \%)$ \\
\hline $\mathrm{N} 2 \mathrm{c}$ & $6(16 \%)$ \\
\hline N3 & $5(14 \%)$ \\
\hline \multicolumn{2}{|c|}{ Tumor differentiation } \\
\hline Well & $7(19 \%)$ \\
\hline Moderately & $26(70 \%)$ \\
\hline Poorly & $4(11 \%)$ \\
\hline
\end{tabular}

PS, piriformis sinus; PC, post cricoid; PW, posterior wall.

concentrated); $1 \mu 1$ deoxynucleoside triphosphate (dNTPs, $2 \mathrm{mM}) ; 1 \mu \mathrm{l}$ forward primer $(2 \mathrm{mM}) ; 1 \mu \mathrm{l}$ reverse primer 2 (2 mM); $0.05 \mu 1$ Taq DNA polymerase (Platinum Taq DNA polymerase; Invitrogen, $5 \mathrm{U} / \mu \mathrm{l}) ; 1 \mu \mathrm{l} \mathrm{cDNA}(100 \mathrm{ng} / \mu \mathrm{l})$. Thirty cycles of denaturation $\left(94^{\circ} \mathrm{C}, 1 \mathrm{~min}\right)$, annealing $\left(58^{\circ} \mathrm{C}, 1 \mathrm{~min}\right)$ and extension $\left(72^{\circ} \mathrm{C}, 1 \mathrm{~min}\right)$ were carried out in a DNA thermal cycler (Applied Biosystems GeneAmp 9700; Applied Biosystems, Forster City, CA, USA). Raji cells were used as a negative control for B7-H3, and SK-OV3 cells as a positive control for B7-H3

Flow cytometry. Cell suspensions of HNSCC cells were prepared by trypsin/EDTA treatment and washed three times. One million cells were incubated with $100 \mu \mathrm{l}$ of $10 \mu \mathrm{g} /$ ml mouse anti-human $\mathrm{B} 7-\mathrm{H} 3$-specific monoclonal antibody (376.96) for $60 \mathrm{~min}$ at $4^{\circ} \mathrm{C}$. Isotype mouse IgG2a (Biodesign International, Saco, Maine, USA) was used as control. The cells were washed three times and incubated with phycoerythrin (PE)-goat anti-mouse IgG antibody (R480; Dako, 
Glostrup, Denmark) at 1:100 dilution for $30 \mathrm{~min}$ at $4^{\circ} \mathrm{C}$. After another wash, the cells were subjected to flow cytometric analysis using FACScan (Becton-Dickinson, Franklin Lakes, NJ, USA). All dilutions and washings were done in ice-cold PBS containing $0.1 \%$ sodium azide and $0.5 \%$ BSA. Raji cells were used as a negative control for B7-H3, and SK-OV3 cells as a positive control for B7-H3.

Immunohistological staining. Formalin-fixed and paraffinembedded specimens were obtained from surgical biopsies at the pretreatment period. The specimens were cut in $5 \mu \mathrm{m}$ sections. The slides were deparaffinized in xylane and ethanol. These sections were then incubated with $3 \%$ hydrogen peroxide for $30 \mathrm{~min}$. The slides were placed in $10 \mathrm{mM}$ citric acid buffer at $\mathrm{pH} 6.0$ and underwent antigen retrieval for $10 \mathrm{~min}$ at $750 \mathrm{~W}$ and $95^{\circ} \mathrm{C}$ in a microwave oven. Mouse monoclonal antibody specific to B7-H3 (clone 376.96; provided by Dr S. Ferrone Department of Surgery, University of Pittsburgh Cancer Institute, Pittsburgh, USA; $5 \mu \mathrm{g} / \mathrm{ml}$ ) was used. This primary antibody was incubated for overnight at $4^{\circ} \mathrm{C}$, followed by incubation with peroxidase labeled dextran polymer (EnVision ${ }^{+}$; Dako A/S, Carpinteria, CA) for $30 \mathrm{~min}$ at room temperature. They were visualized by immersing the slides in freshly prepared $0.02 \%$ diaminobenzidine solution for $10 \mathrm{~min}$. The sections were finally counterstained with Lillie-Mayer's hematoxylin and mounted. For the staining of human CD8 T-cells, mouse monoclonal human CD8-specific antibody (Clone C8/144B; Dako A/S; 1:100 dilution) was used and incubated overnight at $4^{\circ} \mathrm{C}$. Sections were washed thrice in PBS, followed by incubation with peroxidase-labeled dextran polymer (EnVision+; Dako A/S) for 30 min at room temperature. The counter staining was demonstrated as described above.

Evaluation of immunohistological staining. The sections were examined microscopically by three of the authors without knowledge of clinicopathological features. Each sample was throughly evaluated at a magnification of $x 100$. The expression of B7-H3 was categorized in 4 grades according to previous report (13); score 3 (strong): when strong membranous expression of the molecule was present, score 2 (moderate): when incomplete and discontinuous moderate membranous expression was present, score 1 (weak): when either cytoplasmic expression or rare membranous condensation was present, score 0 (none): $<5 \%$ of tumor cells demonstrated expression. To count $\mathrm{CD}^{+} \mathrm{T}$-cells in hypopharyngeal SCC tissues, three randomly selected tumor areas were counted at x200 magnification, and the average count was calculated (30).

Statistical analysis. Correlation between two variables was tested by Spearman rank correlation coefficient and was summarized with the appropriate p-value. Two groups were compared using Mann-Whitney U-test, and were summarized with their appropriate p-value. Time was defined as the period until cause-specific death or last follow-up. The probabilities of cause-specific survival were calculated using Kaplan-Meier method and compared using log-rank test. For determination of factors related to cause specific survival, a Cox proportional hazards model was used. The final results of these analyses are hazard ratios (HR), their $95 \%$ confidence intervals (CI) and p-value. The p-values $<0.05$ were considered to be statistically significant.

\section{Results}

Expression of B7-H3 in HNSCC cells. Four different HNSCC cell lines (HPC-92Y, SAS, PCI-13 and PCI-30 cells) were evaluated for mRNA expressions of B7-H3 by RT-PCR. Expression of B7-H3 mRNA was found clearly in 4 HNSCC cell lines regardless of its origin (Fig. 1A). After identifying B7-H3 mRNA in 4 HNSCC cell lines, we performed flow cytometric analysis for cell surface expression of B7-H3 protein. Cell surface expression of B7-H3 protein was found in all 4 HNSCC cell lines (Fig. 1B).

B7-H3 expression was detected in hypopharyngeal SCC tissues. Total 37 tissue sections from patients with hypopharyngeal SCC were determined. The B7-H3 expression was hardly detected on normal head and neck epithelium adjacent to primary tumor. In hypopharyngeal SCC tissues, B7-H3 was mainly expressed on cell surface and cytoplasm of carcinoma cells. The B7-H3 expression on primary carcinoma cells was detected at various levels (score 1-3) in 32 patients (86\%), and was not detected in five patients (score 0; Fig. 2A). In 13 patients (35\%) weak expression (score 1; Fig. 2B), in 11 patients $(28 \%$ ) a moderate expression (score 2; Fig. 2C), in 8 patients (22\%) strong expression (score 3) of B7-H3 (Fig. 2D) were detected in the intra-tumor area.

Clinical outcome of patients with hypopharyngeal SCC. All 37 patients studied underwent radical therapies. Twelve patients $(32 \%)$ were treated with combined therapy that was comprised of preoperative radiochemotherapy followed by surgical resection. Five patients (14\%) were treated with preoperative irradiation followed by surgical resection. Nine patients $(24 \%)$ were treated with radiochemotherapy. Five patients $(14 \%)$ were treated with irradiation alone. Five patients (14\%) were treated with surgery alone. The remaining 3 patients (8\%) were treated by RADPLAT (36-38). Histological evaluation showed that tumor cells were not present on the surgical margin from any of the 22 patients that underwent surgery. On this evaluation, there were no tumor cells in the biopsy samples obtained from any of the 15 patients after treatments by radiochemotherapy, radiotherapy alone and RADPLAT. Therefore, all patients experienced disease free period. However, $10(27 \%)$ patients developed local recurrence and 11 (30\%) patients developed regional lymph node metastasis. During the follow-up period, 13 patients $(35 \%)$ developed distant metastasis as well. Twentythree $(62 \%)$ patients died during follow-up period; $16(43 \%)$ died of tumor-related disorder and 7 (19\%) patients were tumor free and died from intercurrent diseases. The 5-year tumor-specific survival of 37 patients with hypopharyngeal carcinoma was $48.5 \%$.

Correlation between B7-H3 expression and tumor-infiltrating $C D 8^{+} T$-cells. To determine the potential relevance of $\mathrm{B} 7-\mathrm{H} 3$ expression on the distribution of tumor infiltrating $\mathrm{CD}^{+} \mathrm{T}$-cells in hypopharyngeal SCC, we performed immunohistological staining for CD8 of all 37 hypopharyngeal SCC tissue sections. 
A

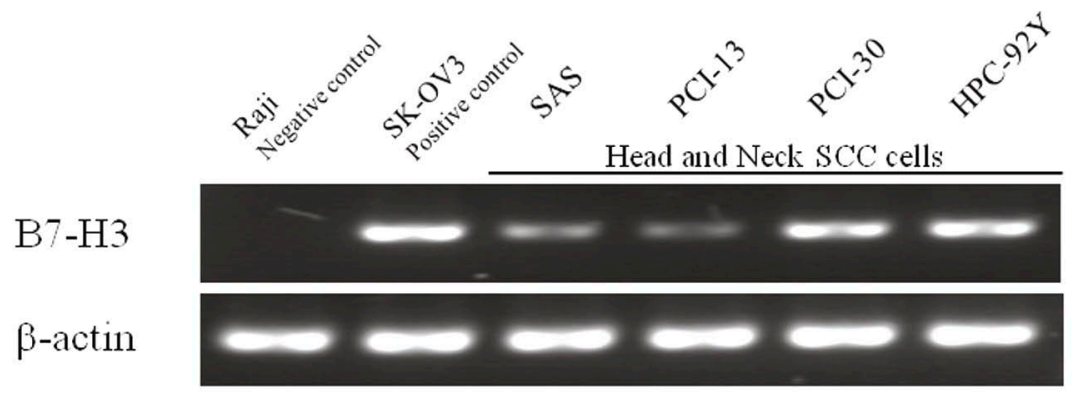

B
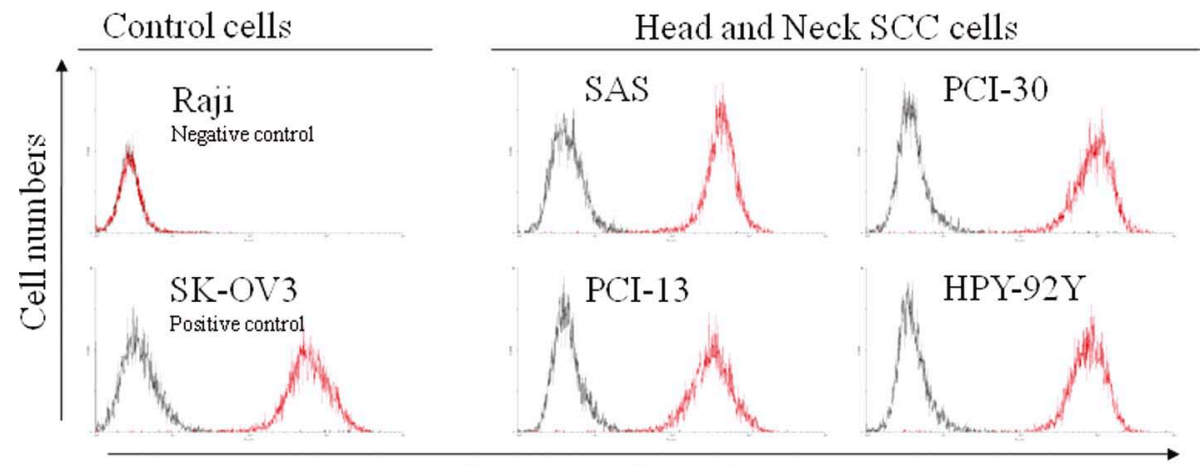

Fluoresence intensity

Figure 1. B7-H3 mRNA expression in four human head and neck SCC cell lines including HPC-92Y derived from hypopharyngeal SCC (A). mRNA expression was measured by reverse transcription-PCR. $\beta$-actin was used as a house-keeping gene. Cell surface expression of B7-H3 protein in four human head and neck SCC cell lines (red line; B). Cell surface expression was measured by flow cytometry. Cells were also incubated with mouse isotype IgG2a (black line; B). Raji cells derived from Burkitt's lymphoma and SK-OV3 cells derived from breast cancer were utilized as negative and positive control cells for B7-H3 expression, respectively.
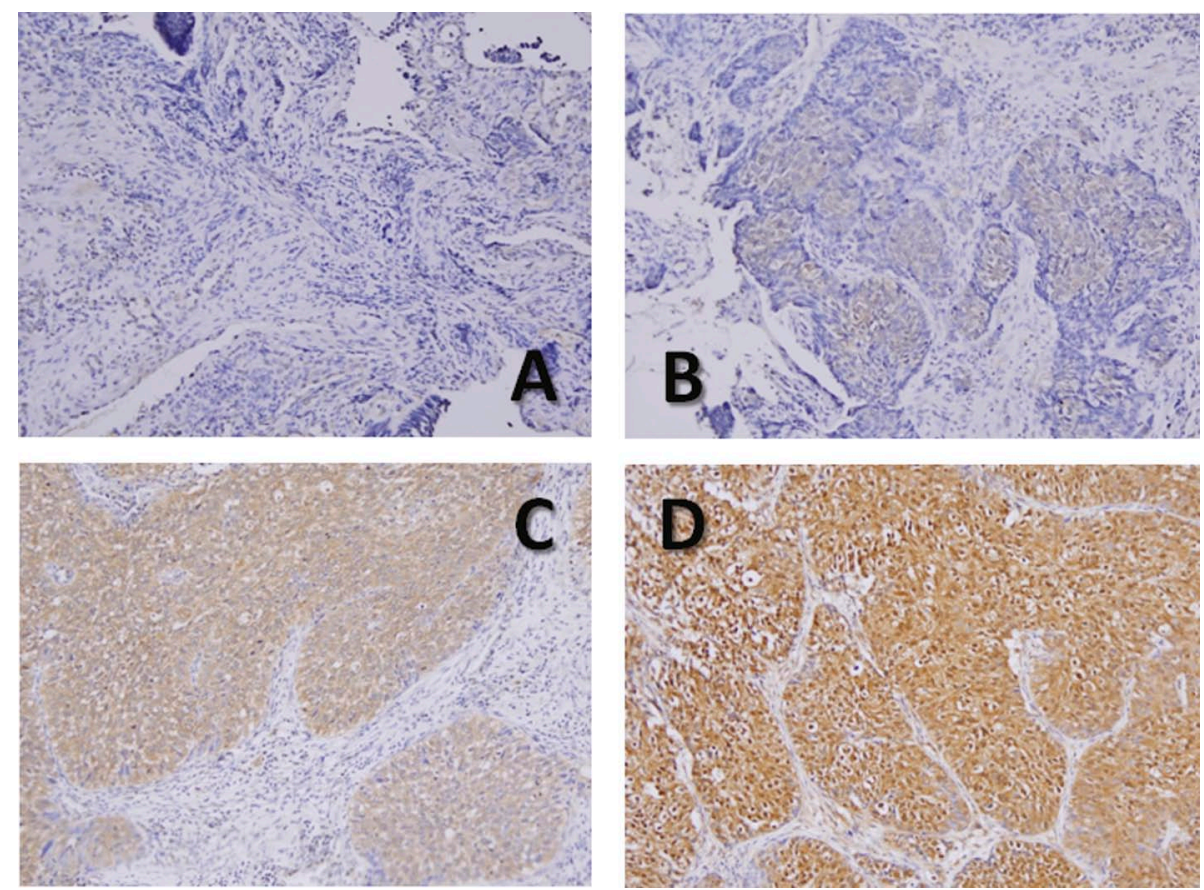

Figure 2. Immunohistological staining of hypopharyngeal SCC tissues for B7-H3 expression. Positive staining was observed in $86 \%$ of the patients with hypopharyngeal SCC. Representative tissues of, none: score 0 (A), weak (B): score 1, moderate (C): score 2, strong staining (D): score 3 for B7-H3 expression in hypopharyngeal SCC are shown. Original magnification, $\mathrm{x} 100$. 


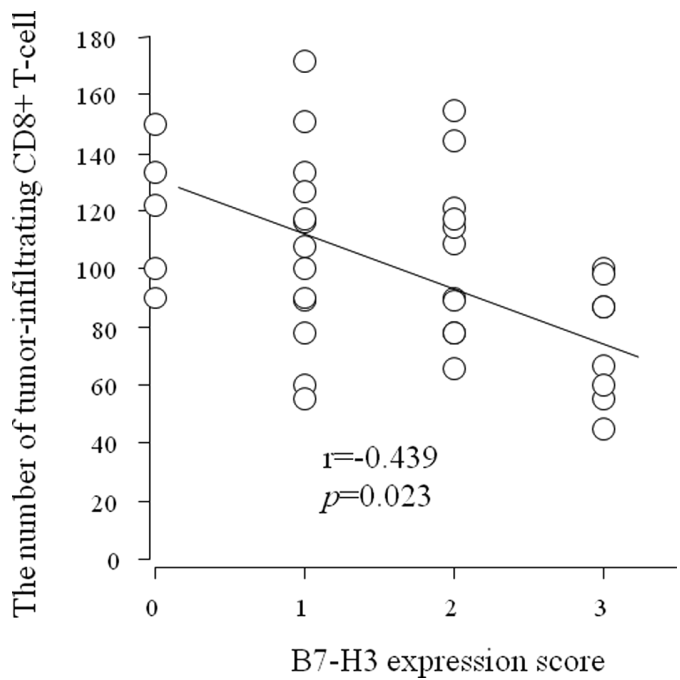

Figure 3. The number of tumor-infiltrating $\mathrm{CD} 8^{+} \mathrm{T}$-cell was inversely correlated with $\mathrm{B} 7-\mathrm{H} 3$ expression score in 37 patients with hypopharyngeal SCC $(\mathrm{r}=-0.439, \mathrm{p}=0.023)$. This correlation was tested by Spearman rank correlation coefficient.

Immunohistological analysis revealed a significant negative correlation between the $\mathrm{B} 7-\mathrm{H} 3$ expression score and the number of tumor infiltrating $\mathrm{CD} 8^{+} \mathrm{T}$-cells $(\mathrm{r}=-0.439, \mathrm{p}=0.023$, Fig. 3).

B7-H3 expression has a prognostic value in patients with hypopharyngeal SCC. Gender, age, histology, T status at diagnosis and initial therapies did not influence the B7-H3 expression. Patients who developed distant metastasis after tumor-free periods showed significantly higher B7-H3 expression scores than patients who did not develop distant metastasis during follow-up periods ( $\mathrm{p}=0.048$; Fig. $4 \mathrm{~A}$ ). The distant metastasis control of patients with B7-H3 score 3 was significantly worse than that of patients with $\mathrm{B} 7-\mathrm{H} 3$ score $0-2(\mathrm{p}=0.040$; Fig. 4B). With regard to correlation between expression of B7-H3 and survival, the expressions of B3-H3 did not influence the over-all survival, and disease-free survival. However, the cause-specific survival of patients with B7-H3 score 3 was significantly worse than that of patients with $\mathrm{B} 7-\mathrm{H} 3$ expression score $0-2$ ( $p=0.028$; Fig. 4C). Univariate analysis also showed that strong B7-H3 expression (score 3 ) as a significant indicator for poor tumor-specific survival $(\mathrm{p}=0.0418)$. Univariate analysis also showed that B7-H3 score 3 was a significant indicator for poor cause-specific survival. Multivariate analysis confirmed that strong B7-H3 expression (score 3) was an independent factor for cause-specific death (hazard ratio: 9.803, confidence interval: $0.018-0.539, \mathrm{p}=0.0110$; Table II).

\section{Discussion}

We present, what is to our knowledge, the first report of expression of co-regulatory molecule B7-H3 in hypopharyngeal SCC. In the present study, we show that B7-H3 was highly expressed in head and neck SCC cell lines including hypopharyngeal SCC cells in vitro. In the immunohistological study, B7-H3 expression was found in $86 \%$ of all 37 patients with hypopharyngeal SCC. B7-H3 expression was inversely correlated with number of tumor-infiltrating CD8 ${ }^{+} \mathrm{T}$-cell. B7-H3 expression was significantly higher in patients who developed distant metastases after
A

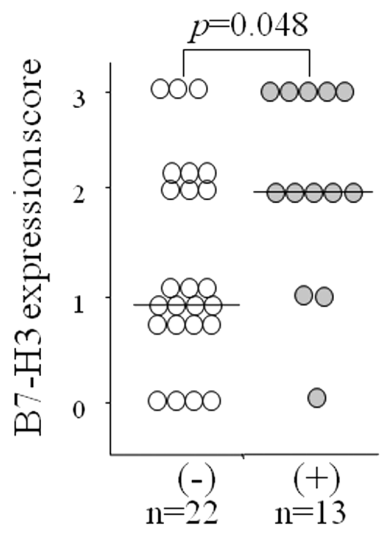

Distant metastasis

Mann Whitney-U test
B
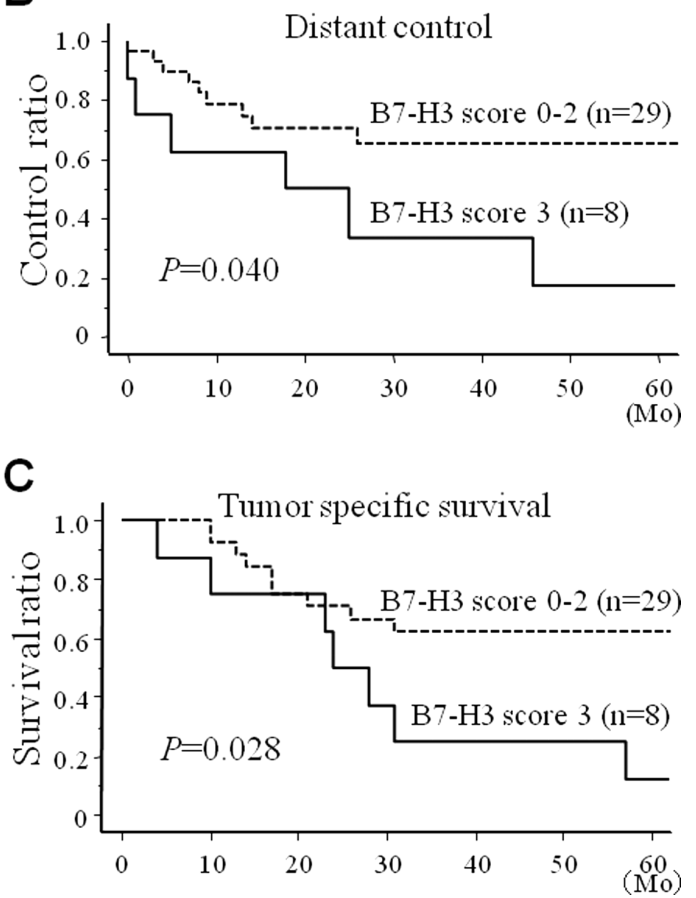

Figure 4. B7-H3 expression score of patients who developed distant metastasis (gray circle; A) was significantly higher than that of patients who did not develop distant metastasis (open circle; $\mathrm{A}, \mathrm{p}=0.048$ ). Mann-Whitney $\mathrm{U}$ test was utilized for determining the $\mathrm{p}$-value. Distant control and tumor-specific survival (solid line; B and C) of patients with B7-H3 score 3 was significantly shorter than that of patients with B7-H3 score 0-2 (broken line; B and C; $\mathrm{p}=0.040$, $\mathrm{p}=0.028$, respectively). Probabilities of distant control and tumor-specific survival were calculated with Kaplan-Meier method and compared with log-rank test. 
Table II. Multivariate Cox proportional hazards analysis for tumor-specific survival of variables in 37 patients with hypopharyngeal squamous cell carcinoma.

\begin{tabular}{lccc}
\hline Variable & Hazard ratio & $95 \%$ CI & p-value \\
\hline Age ( $\geq 60)$ & 1.279 & $0.219-2.873$ & 0.7405 \\
T factor (T3-4) & 1.406 & $0.192-2.672$ & 0.6088 \\
N factor (N2c-3) & 7.192 & $0.034-0.539$ & 0.0057 \\
Brinkman index (>500) & 3.717 & $0.065-1.104$ & 0.0684 \\
Primary site (PS) & 6.250 & $0.020-1.309$ & 0.0875 \\
Pathological diff. (well) & 0.228 & $0.749-25.257$ & 0.1015 \\
B7-H3 expression (strong) & 9.803 & $0.018-0.539$ & 0.0110 \\
\hline
\end{tabular}

CI, confidence interval; diff., differentiation.

radical therapies than in patients who did not develop distant metastasis. The distant control and the tumor-specific survival of patients with high B7-H3 expression were significantly shorter than that of patients with none to intermediate B7-H3 expression. Furthermore, univariate analysis also showed that high B7-H3 expression as a significant indicator for poor tumorspecific survival, and multivariate analysis confirmed that high B7-H3 expression was the independent factor for tumor-specific death.

B7-H3 was discovered as a member of the B7-CD28 family and initially identified as a co-stimulator of T lymphocyte (22). B7-H3 has recently been identified to bind TLT-2 as one of the counter receptors, a molecule belonging to the triggering receptor expressed on myeloid cells (TREM) receptor family. Generally, the TREM family molecules function as modulators of the cellular response and play roles in both innate and adaptive immunity $(39,40)$. TLT- 2 acts as a co-stimulatory TCR for B7-H3. Transduction of TLT-2 into T cells resulted in enhanced IL-2 and IFN- $\gamma$ production via interactions with B7-H3. Blockade of the interaction between B7-H3 and TLT-2 with $\mathrm{mAb}$ against B7-H3 or TLT-2 efficiently inhibited contact hypersensitivity responses mediated by $\mathrm{CD}^{+} \mathrm{T}$ cells (41).

Although the co-inhibitory receptor for B7-H4 has not been identified, the immunological function of $\mathrm{B} 7-\mathrm{H} 3$ is controversial. Subsequent studies suggest that B7-H3 plays inhibitory roles in T-cell activation. Human and mouse B7-H3 fusion proteins inhibit $\mathrm{T}$ lymphocyte activation and effector cytokine production in vitro. The immunoglobulin V-like and immunoglobulin C-like domains of human B7-H3 have been shown to down-regulate both T-cell proliferation and cytokine production in response to $\mathrm{CD} 3 / \mathrm{CD} 28$-mediated co-stimulatory activation (27). It has been reported that B7-H3-deficient mice develop accelerated forms of induced airway inflammation and experimental autoimmune encephalitis, therefore implicating B7-H3 as an inhibitor of Th1-mediated immunity (28). Murine B7-H3 in the presence of anti-CD3 was shown to inhibit murine $\mathrm{CD} 4^{+} \mathrm{T}$-cell activation and interleukin 2 production and this inhabitation was completely abrogated by antibody-mediated B7-H3 blockade (29). Antibody-mediated blockade of B7-H3 also exacerbates experimental autoimmune encephalomyelitis in mice $(28,29)$. Furthermore, B7-H3 has been implicated as an inhibitor of natural killer cell-mediated lysis, and multiple receptors have now been postulated to explain the ability of B7-H3 to inhibit responses by both $\mathrm{T}$ cells and natural killer cells in human neuroblastoma studies (27). Many human cancers are also found to naturally express B7-H3 and recent studies have supported a role of B7-H3 in cancer progression and clinical outcome. Tumor-related B7-H3 expression was abundant in most pancreatic cancer tissues and significantly more intense in case with lymph node metastasis and advanced pathological stage (30). In non-small cell lung cancers, B7-H3 was highly expressed in tissue sumples and significantly correlated with lymphnode metastases (31). B7-H3 immunoreactivity in patients with prostate cancer after radical prostatectomy indicated that increased levels of $\mathrm{B} 7-\mathrm{H} 3$ intensity positively correlated with worse clinical features and prognosis $(13,32)$. B7-H3 immunohistological study might be as a novel tool for the differential diagnosis of small round cell tumors and might be useful in identifying neuroblastoma patients facing the risk of recurrence, and might serve as a reference for more careful follow-up (33). B7-H3 expression in clear cell renal cell carcinoma was observed in both tumor cell and tumor vasculature and significantly associated with an increased risk of tumor-specific death suggesting B7-H3 expression compromise host antitumor immunity (34). The latest report demonstrated that high B7-H3 expression in colorectal carcinoma was positively correlated with advanced tumor grade and negatively correlated with tumor infiltrating $\mathrm{T}$ lymphocytes in an immunohistologic study, and the level of soluble B7-H3 sera from patients was higher than healthy volunteers (35). Reviewing these recent studies and our findings in the present study, although the exact role of B7-H3 in cancer progression has not been fully investigated and remains elusive, B7-H3 expression might play a crucial role in the progression of hypopharyngeal SCC. We put forward a hypothesis that B7-H3 is involved in the suppression of tumor immune response and our data provide some experimental clues favorable to this hypothesis. In the present study, we demonstrated that B7-H3 expression in hypopharyngeal SCC tissue was negatively correlated to number of infiltrating $\mathrm{CD}^{+} \mathrm{T}$ lymphocytes, suggesting that $\mathrm{B} 7-\mathrm{H} 3$ expression on hypopharyngeal SCC cells may inhibit infiltration of T lymphocytes.

An explanation for B7-H3-mediated T cell co-inhibition is that there are unexplored receptor(s) that may be preferentially expressed on tumor cells. In previous studies showed that, the type, density and location of immune cells in head and neck SCC including hypopharyngeal SCC tissues are associated with malignant features of tumors and the patient's survival. A recent report utilizing 240 biopsy samples obtained from total of 115 patients with squamous cell carcinoma of the oroharynx and hypopharynx suggested that higher numbers of intraepithelial $\mathrm{CD}^{+}$TIL led to significantly improved NED-survival (42). Furthermore, studies on the prognostic significance of intratumoral infiltration of $\mathrm{T}$ lymphocytes in different human tumor types were reported. Immunohistological study in 87 patients with oral SCC concluded that in multivariate analysis, the tumor stromal $\mathrm{CD}^{+} \mathrm{T}$ cell/CCR $4^{+}$Treg ratio was an independent prognostic factor (43).

The underlying mechanism of B7-H3 expression in hypopharyngeal SCC has not yet been elucidated. In our current study, RT-PCR analyses indicated that $\mathrm{B}$ - $\mathrm{H} 3$ gene was expressed in all four HNSCC cell lines including 
hypopharyngeal-originated cell line HPC-92Y and flow cytometric analyses indicated that cell-surface B7-H3 expression was expressed in these four head and neck SCC cell lines. Consequently, it was suggested that tumor-associated B7-H3 offers a new therapeutic opportunity for enhancement of antitumor immunity or as a drug target (44), and several reports investigated that B7-H3 may be a therapeutic target in human malignancies. Androgen-ablated patients underwent radical prostatectomy revealed that B7-H3 expression increased in response to hormone therapy relative to untreated lesions in prostate cancer, and may represent an attractive target to improve treatment of prostate cancer (45). Patients treated for recurrent neuroblastoma metastatic to the CNS, received ${ }^{131}$ I-monoclonal antibodies specific for B7H3 following surgery and radiation, showed improved survival (46).

In conclusion, our present study suggests that the co-stimulatory molecule B7-H3 plays a crucial role in hypopharyngeal SCC progression, tumor metastasis resulting in poor prognosis and might be involved in the negative regulation of T-cellmediated tumor immune response. Strong B7-H3 expression was an independent prognostic factor for tumor-specific death in patients with hypopharyngeal SCC. However, further study is required to understand the mechanism underlining the inhibitory function of B7-H3 including discovering the inhibitory receptor for $\mathrm{B} 7-\mathrm{H} 3$, to examine whether increased protein expression of B7-H3 in tumor could be useful in immunotherapeutic approaches.

\section{Acknowledgments}

We thank Professor Soldano Ferrone (Department of Surgery, University of Pittsburgh Cancer Institute, Pittsburgh, USA) for his excellent expert suggestions and providing antibody and cancer cell lines. We also thank Dr Syunsuke Yanoma (Yokohama Tsurugamine Hospital) for providing the hypopharyngeal SCC cell line. This work was supported by Grant-in-Aid (no. 21791583) for scientific research from the Ministry of Education, Science and Culture, Japan.

\section{References}

1. Wycliffe ND, Grover RS, Kim PD and Simental A Jr: Hypopharyngeal cancer. Top Magn Reson Imaging 18: 243-258, 2007.

2. Hall SF, Groome PA, Irish J and O'Sullivan B: The natural history of patients with squamous cell carcinoma of the hypopharynx. Laryngoscope 118: 1362-1371, 2008.

3. Hoffman HT, Karnell LH, Shah JP, et al: Hypopharyngeal cancer patient care evaluation. Laryngoscope 107: 1005-1017, 1997.

4. Kraus DH, Zelefsky MJ, Brock HA, Huo J, Harrison LB and Shah JP: Combined surgery and radiation therapy for squamous cell carcinoma of the hypopharynx. Otolaryngol Head Neck Surg 116: 637-641, 1997.

5. Thompson RH, Dong H, Lohse CM, et al: PD-1 is expressed by tumor-infiltrating immune cells and is associated with poor outcome for patients with renal cell carcinoma. Clin Cancer Res 13: 1757-1761, 2007.

6. Nakanishi J, Wada Y, Matsumoto K, Azuma M, Kikuchi K and Ueda S: Overexpression of B7-H1 (PD-L1) significantly associates with tumor grade and postoperative prognosis in human urothelial cancers. Cancer Immunol Immunother 56: 1173-1182, 2007.

7. Inman BA, Sebo TJ, Frigola X, et al: PD-L1 (B7-H1) expression by urothelial carcinoma of the bladder and BCG-induced granulomata: associations with localized stage progression. Cancer 109: 1499-1505, 2007
8. Krambeck AE, Thompson RH, Dong H,et al: B7-H4 expression in renal cell carcinoma and tumor vasculature: associations with cancer progression and survival. Proc Natl Acad Sci USA 103: 10391-10396, 2006.

9. Hirano F, Kaneko K, Tamura H, et al: Blockade of B7-H1 and PD-1 by monoclonal antibodies potentiates cancer therapeutic immunity. Cancer Res 65: 1089-1096, 2005.

10. Thompson RH, Kuntz SM, Leibovich BC, et al: Tumor B7-H1 is associated with poor prognosis in renal cell carcinoma patients with long-term follow-up. Cancer Res 66: 3381-3385, 2006.

11. Thompson RH, Webster WS, Cheville JC, et al: B7-H1 glycoprotein blockade: a novel strategy to enhance immunotherapy in patients with renal cell carcinoma. Urology 66: 10-14, 2005.

12. Thompson RH, Gillett MD, Cheville JC, et al: Costimulatory B7-H1 in renal cell carcinoma patients: Indicator of tumor aggressiveness and potential therapeutic target. Proc Natl Acad Sci USA 101: 17174-17179, 2004.

13. Zang X, Thompson RH, Al-Ahmadie HA, et al: B7-H3 and B7x are highly expressed in human prostate cancer and associated with disease spread and poor outcome. Proc Natl Acad Sci USA 104: 19458-19463, 2007.

14. Dong H, Strome SE, Salomao DR, et al: Tumor-associated B7-H1 promotes T-cell apoptosis: a potential mechanism of immune evasion. Nat Med 8: 793-800, 2002.

15. Dong H, Zhu G, Tamada K and Chen L: B7-H1, a third member of the B7 family, co-stimulates T-cell proliferation and interleukin-10 secretion. Nat Med 5: 1365-1369, 1999.

16. Uppaluri R, Dunn GP and Lewis JS Jr: Focus on TILs: prognostic significance of tumor infiltrating lymphocytes in head and neck cancers. Cancer Immun 8: 16, 2008.

17. Whiteside TL: The tumor microenvironment and its role in promoting tumor growth. Oncogene 27: 5904-5912, 2008.

18. Cho Y, Miyamoto $\mathrm{M}$, Kato $\mathrm{K}$, et al: $\mathrm{CD}^{+}$and $\mathrm{CD}^{+} \mathrm{T}$ cells cooperate to improve prognosis of patients with esophageal squamous cell carcinoma. Cancer Res 63: 1555-1559, 2003.

19. Eerola AK, Soini Y and Paakko P: A high number of tumorinfiltrating lymphocytes are associated with a small tumor size, low tumor stage, and a favorable prognosis in operated small cell lung carcinoma. Clin Cancer Res 6: 1875-1881, 2000.

20. Naito $Y$, Saito $K$, Shiiba K, et al: $C D 8^{+} T$ cells infiltrated within cancer cell nests as a prognostic factor in human colorectal cancer. Cancer Res 58: 3491-3494, 1998.

21. Brandwein-Gensler M, Teixeira MS, Lewis CM, et al: Oral squamous cell carcinoma: histologic risk assessment, but not margin status, is strongly predictive of local disease-free and overall survival. Am J Surg Pathol 29: 167-178, 2005.

22. Chapoval AI, Ni J, Lau JS, et al: B7-H3: a costimulatory molecule for $\mathrm{T}$ cell activation and IFN-gamma production. Nat Immunol 2: 269-274, 2001.

23. Luo L, Chapoval AI, Flies DB, et al: B7-H3 enhances tumor immunity in vivo by costimulating rapid clonal expansion of antigen-specific $\mathrm{CD}^{+}$cytolytic T cells. J Immunol 173: 5445-5450, 2004.

24. Lupu CM, Eisenbach C, Kuefner MA, et al: An orthotopic colon cancer model for studying the B7-H3 antitumor effect in vivo. J Gastrointest Surg 10: 635-645, 2006

25. Ma L, Luo L, Qiao H, et al: Complete eradication of hepatocellular carcinomas by combined vasostatin gene therapy and B7H3-mediated immunotherapy. J Hepatol 46: 98-106, 2007.

26. Sun X, Vale M, Leung E, Kanwar JR, Gupta R and Krissansen GW: Mouse B7-H3 induces antitumor immunity. Gene Ther 10: 1728-1734, 2003.

27. Castriconi R, Dondero A, Augugliaro R, et al: Identification of 4Ig-B7-H3 as a neuroblastoma-associated molecule that exerts a protective role from an NK cell-mediated lysis. Proc Natl Acad Sci USA 101: 12640-12645, 2004.

28. Suh WK, Gajewska BU, Okada H, et al: The B7 family member B7-H3 preferentially down-regulates $\mathrm{T}$ helper type 1-mediated immune responses. Nat Immunol 4: 899-906, 2003.

29. Prasad DV, Nguyen T, Li Z, et al: Murine B7-H3 is a negative regulator of T cells. J Immunol 173: 2500-2506, 2004.

30. Yamato I, Sho M, Nomi T, et al: Clinical importance of B7-H3 expression in human pancreatic cancer. Br J Cancer 101: 1709-1716, 2009.

31. Sun Y, Wang Y, Zhao J, et al: B7-H3 and B7-H4 expression in non-small-cell lung cancer. Lung Cancer 53: 143-151, 2006.

32. Roth TJ, Sheinin Y, Lohse CM, et al: B7-H3 ligand expression by prostate cancer: a novel marker of prognosis and potential target for therapy. Cancer Res 67: 7893-7900, 2007. 
33. Gregorio A, Corrias MV, Castriconi R, et al: Small round blue cell tumours: diagnostic and prognostic usefulness of the expression of B7-H3 surface molecule. Histopathology 53: 73-80, 2008.

34. Crispen PL, Sheinin Y, Roth TJ, et al: Tumor cell and tumor vasculature expression of $\mathrm{B} 7-\mathrm{H} 3$ predict survival in clear cell renal cell carcinoma. Clin Cancer Res 14: 5150-5157, 2008.

35. Sun J, Chen LJ, Zhang GB, et al: Clinical significance and regulation of the costimulatory molecule B7-H3 in human colorectal carcinoma. Cancer Immunol Immunother 59: 1163-1171, 2010.

36. Robbins KT, Storniolo AM, Kerber C, et al: Phase I study of highly selective supradose cisplatin infusions for advanced head and neck cancer. J Clin Oncol 12: 2113-2120, 1994.

37. Robbins KT, Kumar P, Regine WF, et al: Efficacy of targeted supradose cisplatin and concomitant radiation therapy for advanced head and neck cancer: the Memphis experience. Int J Radiat Oncol Biol Phys 38: 263-271, 1997.

38. Robbins KT, Kumar P, Wong FS, et al: Targeted chemoradiation for advanced head and neck cancer: analysis of 213 patients. Head Neck 22: 687-693, 2000

39. King RG, Herrin BR and Justement LB: Trem-like transcript 2 is expressed on cells of the myeloid/granuloid and B lymphoid lineage and is up-regulated in response to inflammation. $\mathrm{J}$ Immunol 176: 6012-6021, 2006.

40. Klesney-Tait J, Turnbull IR and Colonna M: The TREM receptor family and signal integration. Nat Immunol 7: 1266-1273, 2006.
41. Hashiguchi M, Kobori H, Ritprajak P, Kamimura Y, Kozono H and Azuma M: Triggering receptor expressed on myeloid cell-like transcript 2 (TLT-2) is a counter-receptor for B7-H3 and enhances T cell responses. Proc Natl Acad Sci USA 105: 10495-10500, 2008.

42. Distel LV, Fickenscher R, Dietel K, et al: Tumour infiltrating lymphocytes in squamous cell carcinoma of the oro- and hypopharynx: prognostic impact may depend on type of treatment and stage of disease. Oral Oncol 45: e167-174, 2009.

43. Watanabe Y, Katou F, Ohtani H, Nakayama T, Yoshie O and Hashimoto K: Tumor-infiltrating lymphocytes, particularly the balance between CD8(+) T cells and CCR4(+) regulatory $T$ cells, affect the survival of patients with oral squamous cell carcinoma. Oral Surg Oral Med Oral Pathol Oral Radiol Endod 109: 744-752, 2010.

44. Zang X and Allison JP: The B7 family and cancer therapy: costimulation and coinhibition. Clin Cancer Res 13: 5271-5279, 2007.

45. Chavin G, Sheinin Y, Crispen PL, et al: Expression of immunosuppresive B7-H3 ligand by hormone-treated prostate cancer tumors and metastases. Clin Cancer Res 15: 2174-2180, 2009.

46. Kramer K, Kushner BH, Modak S, et al: Compartmental intrathecal radioimmunotherapy: results for treatment for metastatic CNS neuroblastoma. J Neurooncol 97: 409-418, 2010. 